\title{
Intestinal obstruction: a rare complication of channeling Transurethral Resection of the Prostate (TURP): a case report AA Popoola*1, KA Onawola ${ }^{1}$, MD Adesina ${ }^{2}$ and IO Olaoye ${ }^{2}$
}

\author{
Address: ${ }^{1}$ Urology Division, Department of Surgery, University of Ilorin Teaching Hospital, Ilorin, Nigeria and ${ }^{2}$ General Surgery Division, \\ Department of Surgery, University of Ilorin Teaching Hospital, Ilorin, Nigeria \\ Email: AA Popoola* - ademola67@yahoo.com; KA Onawola - onawolakayode@yahoo.co.uk; MD Adesina - mdadesinadr@yahoo.com; \\ IO Olaoye - ademola67@yahoo.com \\ * Corresponding author
}

Published: 29 January 2008

Journal of Medical Case Reports 2008, 2:30 doi:10.1 186/1752-1947-2-30
Received: 12 September 2007

Accepted: 29 January 2008

This article is available from: http://www.jmedicalcasereports.com/content/2/1/30

(C) 2008 Popoola et al; licensee BioMed Central Ltd.

This is an Open Access article distributed under the terms of the Creative Commons Attribution License (http://creativecommons.org/licenses/by/2.0), which permits unrestricted use, distribution, and reproduction in any medium, provided the original work is properly cited.

\begin{abstract}
Introduction: Channeling transurethral resection of the prostate is a recognized form of adjunctive treatment in the treatment of patients with prostate cancer. Despite the fact that complications arising from the procedure have been on the decline, rare complications like intestinal obstruction may occur.
\end{abstract}

Case presentation: This is a case report of a 56 year old man who developed mechanical intestinal obstruction few days after a channeling TURP for advanced $\mathrm{CaP}$.

Conclusion: The report highlights the possibility of intestinal obstruction as a secondary event following a silent urinary bladder perforation during channeling TURP. Early recognition and intervention were responsible for the good outcome in this patient.

\section{Introduction}

Transurethral resection of the prostate (TURP) represents the accepted standard of surgical therapy for the management of symptomatic bladder outlet obstruction due to benign prostatic hyperplasia (BPH) [1]. Limited or Channeling TURP is also a recognized form of adjunctive treatment in the patients with Prostate cancer (CaP) [2-4]. The procedure is used in such patients to relieve urinary retention, though about $50 \%$ of patients will pass urine per urethram without catheters after varying lengths of time after hormonal ablation therapy alone[5]. Channeling TURP is associated with complications, which include urinary bladder perforation $[6,7]$. However, the procedure has become safer over the years in many institutions; hence the complications rates from the procedure have dropped significantly $[8,9]$. Intestinal obstruction is a very rare complication of TURP as suggested by the scarcity of reports in our search of the medical literatures. We therefore wish to use this case report to highlight the possibility of intestinal obstruction as a secondary complication of urinary bladder perforation.

\section{Case presentation}

A 56-year-old man presented to our unit 6 days after he had a channeling TURP and bilateral orchidectomy performed at another centre. He presented with generalized colicky abdominal pain, abdominal distension and constipation. Though the symptoms started on the first day after the operation, they were not severe and he was discharged from the hospital three days postoperatively. There were associated vomiting, anorexia and hiccoughs, which all started on the fifth day after surgery. The urethral catheter was removed on the third postoperative day and he experienced a significant improvement in his uri- 
nary symptoms. He had no known history of hypertension or diabetes patient and there was no previous history of intra-abdominal operations

Clinical examination at presentation revealed mild pallor, fever $\left(\mathrm{T}-37.8^{\circ} \mathrm{C}\right)$, and bilateral peri-orbital and pedal swellings. The pulses were normal but blood pressure was $170 / 100 \mathrm{mmHg}$. The abdomen was distended but soft with no areas of tenderness. Percussion notes were tympanitic and the bowel sounds were hyperactive. Digital rectal examination revealed an enlarged nodular prostate and the rectum contained soft brownish stool. The absent testes and the healing scrotal wound were noted. There was no neuromuscular abnormality.

His hemoglobin was $11.2 \mathrm{~g} / \mathrm{dL}$; the white cell count was $10.8 \times 10^{\%} / \mathrm{L}$, (neutrophilia of $73 \%$ ) and platelet count of $258 \times 10^{\%} / \mathrm{L}$. He had evidence of renal impairment: serum urea was $28.2 \mathrm{mMol} / \mathrm{L}$ (normal range: $2.5-6.5 \mathrm{mMol} / \mathrm{L}$ ) and serum creatinine level was $744 \mu \mathrm{mol} / \mathrm{L}$ (53-106 $\mu \mathrm{Mol} / \mathrm{l}$ ). He was hyponatraemic (Sodium $126 \mathrm{mMol} / \mathrm{L}$ ) (135-145 mMol/L) and slightly hyperkalaemic (Potassium, $5.1 \mathrm{mMol} / \mathrm{L})(2.9-5.0 \mathrm{mMol} / \mathrm{L})$, Urinary specific gravity was normal. Abdominal radiographs revealed features of intestinal obstruction, with gaseous distension of the bowel especially of the small bowel with multiple air fluid levels and paucity of gas in the pelvis (see Figures 1 and 2). Abdomino-pelvic ultrasound scanning revealed bilateral moderate hydronephrosis, a thickened urinary bladder wall with irregularity in its lower segment and remnants of the prostate gland. Urine microbiology culture yielded growth of klebsiella pneumoniae, which was sensitive to ceftazidime and amoxicillin-clavulanic acid combination.

It was apparent that the patient had intestinal obstruction occurring after the Channel TURP with obstructive nephropathy. Initially, conservative management was instituted vis a vis nothing by mouth, intravenous fluids (normal saline alternating with 5\% dextrose-saline), and intravenous antibiotics using a combination of ceftazidime and metronidazole. The gastro-intestinal tract was decompressed by passing a naso-gastric tube for continuous drainage. A size 18 Fr Foley urethral catheter was passed to monitor the patient's urine output and to decompress the upper urinary tract.

The patient's renal function improved significantly with the conservative management but the abdominal pain and distension persisted and got worse. On the tenth day of admission, he had an exploratory laparotomy. Findings at laparotomy were distended small bowel loops and multiple adhesions involving the dome of the bladder, the small intestine and the large omentum. Adhesiolysis was done and the intestinal loops were released. The post-

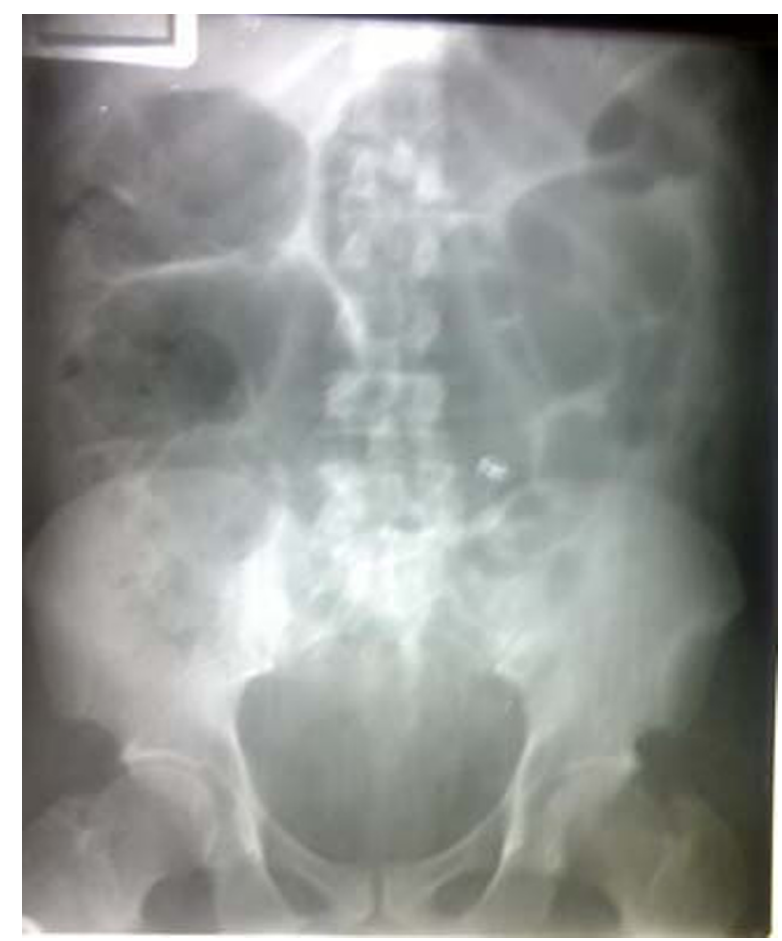

Figure I

Supine shows distended bowel loops.

operative period was uneventful and he was commenced on graded oral diet on the third postoperative day after which he moved his bowel on the same day. The renal status of the patient continued to improve and urethral catheter was removed on the tenth postoperative day, and the patient voided satisfactorily. The serum electrolyte and urea levels at discharge were all within normal ranges (Sodium, $135 \mathrm{mMol} / \mathrm{L}$; Potassium, $4.4 \mathrm{mMol} / \mathrm{L}$; Urea-4.8 $\mathrm{mMol} / \mathrm{L}$ and creatinine $-88 \mu \mathrm{Mol} / \mathrm{L})$. The patient was discharged from the hospital on antihypertensive medications 22 days after admission. He was seen in the out patient department six months after discharge and his condition had remained satisfactory.

\section{Discussion}

Trans urethral resection of the prostate (TURP) has been recognized as an adjuvant therapy in the management of advanced prostate cancer. This is mainly to create a channel in the obstructive tumour thereby relieving the urinary retention. This may be carried out on the patient parri passu with the hormonal ablation therapy to relieve urinary retention. Hormonal ablation alone usually results in the relief of urinary retention in about $50 \%$ of patients after varying periods of urethral catheterization. This cannot always be guaranteed. Channeling TURP can be preemptive when it is carried out about the time when the 


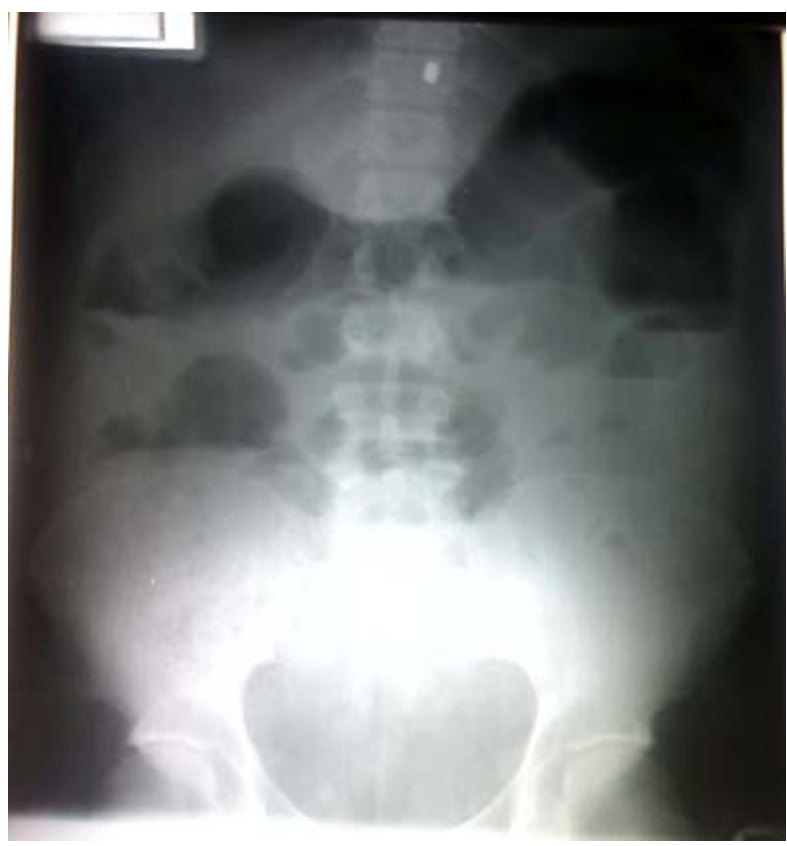

Figure 2

Erect film shows multiple air-fluid levels.

hormonal ablation is initiated as in the case presented. It may also be indicated when the patient's urinary retention is not relieved after a reasonable period after initiating hormonal ablation. Urinary bladder perforation is one of the complications of the procedure [10] and it occurs in less than $1 \%$ of cases in some series $[8,11]$. Most cases of bladder perforation from TURP are managed conservatively by continuous drainage of the urinary bladder, when recognized early. However, some cases of perforation may be missed with no repercussions especially when there are other reasons to keep the urethral catheters on for several days after TURP [11]. Reports of secondary complications resulting from perforation of the urinary bladder have been reported. These are extravesical tumor recurrence [12] intraperitoneal extravasation of irrigating fluid[13] and transurethral resection (TUR) syndrome[14]. The patient in this report sustained an intraperitoneal perforation of the urinary bladder, which was not recognized immediately after the TURP. The greater omentun, in a bid to seal off the perforation on the dome of the bladder, entangled the intestine with the resultant intestinal obstruction. Early recognition and intervention in the management of this complication was responsible for the good outcome in the management of this patient with impaired renal function from the chronic bladder outlet obstruction.

\section{Conclusion}

TURP will remain an important adjunct in the management of patients with advanced CaP. Although, the TURP over the years has become a safe procedure in most experienced hands, possibility of complications occurring should always be borne in mind. Early recognition and management of such complications usually result in good outcome.

\section{Abbreviations}

TURP - Transurethral resection of the prostate; CaP Cancer of the prostate; $\mathrm{Fr}$ - French gauge; $\mathrm{mMol} / \mathrm{L}$ - Millimole/Litre; $\mu \mathrm{Mol} / \mathrm{L}$ - Micromole/Litre.

\section{Competing interests}

The author(s) declare that they have no competing interests.

\section{Authors' contributions}

AAP initiated the concept, literature search and write up of the manuscript. KAO involved in case summary. MDA contributed in clinical management of patient and gave approval for final write up. IOO contributed in clinical management of patient and gave approval for final write up. All authors read and approved the final manuscript.

\section{Consent}

Written informed consent was obtained from the patient for publication of this case report and any accompanying images. A copy of the written consent is available for review by the Editor-in-Chief of this journal.

\section{Acknowledgements}

The authors appreciates the participations of the Doctors in the two surgical units who participated in the management of this patient, thereby making it possible to report on him.

\section{References}

I. Cattolica EV, Sidney S, Sadler MC: The safety of transurethral prostatectomy: a cohort study of mortality in 9416 men. J urol 1997, I58:102-4.

2. Sehgal A, Mandhani A, Gupta N, Dubey D, Srivastava A, Kapoor R, Kumar A: Can the Need for Palliative Transurethral Prostatic Resection in Patients with Advanced Carcinoma of the Prostate Be Predicted? J Endourol 2005, I 9(5):546-9.

3. Gnanapragasam VJ, Kumar V, Langton D, Pickard RS, Leung HY: Outcome of transurethral prostatectomy for the palliative management of lower urinary tract symptoms in men with prostate cancer. International Journal of Urology 2006, I 3(6):7 I I-5.

4. Flam TA, Peyromaure M, Chauveinc L, Thiounn N, Firmin F, Cosset JM, Bernard D: Post-brachytherapy transurethral resection of the prostate in patients with localized prostate cancer. J Urol 2004, I72(I): 108-II.

5. Varenhorst E, Alund G: Urethral obstruction secondary to carcinoma of prostate: response to endocrine treatment. Urology 1985, 25:354-356.

6. Barbieri A, Simonazzi M, Marcato C, Larini P, Barbagallo M, Frattini A, Cortellini P: Massive Hematuria after Transurethral Resection of the Prostate: Management by Intra-Arterial Embolization. Urol Int 2002, 69:318-20.

7. Suzuki $Y$, Nakada T, Ishigooka M, Hashimoto T, Abe $Y$, Sasagawa I, Kubota Y: Pelvic Arteriovenous Aneurysm Caused by 
Transurethral Resection of the Prostate: Successful Management by Intra-Arterial Embolization. Urol Int 1998, 60: 191- I 93.

8. Lim KB, Wong MYC, Foo KT: Transurethral resection of prostate (TURP) through the decades - a comparison of results over the thirty years in a single institution in Asia. Ann Acad Med Singapore 2004, 33:775-9.

9. Ignatoff JM, O'Conor J: Complications of transurethral resection of prostate. Int J urol and neph 1997, 9(I):33-40.

10. Uchida T, Adachi K, Ao T, Fujino A, Omata T, Yoshizawa K, Kurokawa J, Kadowaki K, Shoji K, Yokoyama E: Pre-operative, operative and postoperative complications in 2266 cases of transurethral resection of the prostate. Nippon Hinyokika Gakkai Zasshi 1993, 84(5):897-905.

1I. Martov AG, Kornienko Sl, Gushchin BL, Ergakov DV, Sazonov OA: Intraoperative urological complications in transurethral surgical interventions on the prostate for benign hyperplasia. Urologiia 2005:3-8.

12. Skolarikos A, Chrisofos M, Ferakis N, Papatsoris A, Dellis A, Deliveliotis $C$ : Does the management of bladder perforation during transurethral resection of superficial bladder tumors predispose to extravesical tumor recurrence? J Urol 2005, 173(6): 1908-II.

13. Weber S, Acuff JH, Mazloomdoost M, Kirimli BI: Transurethral prostatectomy complicated by intraperitoneal extravasation of irrigating fluid. Can J Anest 1987, 34:193-5.

14. Dorotta I, Basali A, Ritchey M, O'Hara JF, Sprung J: Transurethral resection syndrome after bladder perforation. Anesth Analg 2003, 97:1536-8.

Publish with Bio Med Central and every scientist can read your work free of charge

"BioMed Central will be the most significant development for disseminating the results of biomedical research in our lifetime. "

Sir Paul Nurse, Cancer Research UK

Your research papers will be:

- available free of charge to the entire biomedical community

- peer reviewed and published immediately upon acceptance

- cited in PubMed and archived on PubMed Central

- yours - you keep the copyright 